\title{
Considerações sobre a obtenção e o uso do plasma rico em plaquetas e das células mesenquimais indiferenciadas em enxertos ósseos
}

\author{
Isolation and use of platelet rich plasma and indiferenciate mesenchimal cells in bone grafts
}

\author{
Geane Maciel Pagliosa $^{\mathrm{I}^{*}}$ Geraldo Eleno Silveira Alves $^{\mathrm{I}}$
}

\section{- REVISÃO BIBLIOGRÁFICA -}

\section{RESUMO}

O plasma rico em plaquetas (PRP) e as células mesenquimais indiferenciadas (CMIs), também chamadas de células-tronco, têm sido amplamente estudados por seus potenciais altos de osteoindução em enxertos ósseos. No entanto, a utilização do PRP e das CMIs deve ser realizada com critério, baseando-se na adequada metodologia de isolamento $e$ utilização. A metodologia inadequada pode ser um fator determinante na eficácia em enxertos ósseos, o que pode justificar alguns resultados controversos da utilização do PRP e das CMIs em enxertos ósseos.

Palavras-chave: células-tronco, plaquetas, osteoindução.

\section{ABSTRACT}

The rich platelet plasma (RPP) and indiferenciate mesenchimal cells (IMCs), or stem cells, have been widely studied because of their high potential of osteoinduction in bone grafts. However, the utilization of RPP and IMCs must be done following correct methodology of isolation and use. The inappropriate methodology can be a determinant factor of its efficacy on bone grafts and can explain some controversial results of its utilization in bone grafts.

Key words: stem cells, platelets, osteoinduction.

\section{INTRODUÇÃO}

Os enxertos auxiliam na incorporação de tecido ósseo em uma região fraturada por meio de quatro mecanismos: suporte mecânico, osteocondução, osteogênese e osteoindução, dependendo do tipo de enxerto utilizado (MARTINEZ \& WALKER, 1999). A osteoindução é um dos mecanismos mais pesquisados atualmente destacandose entre as novas tecnologias de enxerto ósseo.

A osteoindução é a diferenciação de células mesenquimais indiferenciadas (CMIs), também chamadas de células tronco, em células osteogênicas, após contato com a matriz óssea (MARTINEZ \& WALKER, 1999). As CMIs são células multipotenciais presentes em vários tecidos orgânicos e, em especial, na medula óssea (STOCUM, 2001). A diferenciação e a proliferação das CMI em células osteogênicas são moduladas por alguns fatores, em especial os fatores de crescimento.

Fatores de crescimento (FCs) são polipeptídeos específicos, presentes no plasma e em alguns tecidos, que regulam a diferenciação e a proliferação celulares e, portanto, a regeneração dos tecidos (WISLTFALK et al., 2004). Os FCs podem ter ação parácrina, endócrina ou autócrina, e seu estímulo é transmitido via receptores de superfície de membrana, que ativam proteínas reguladoras no citoplasma, gerando respostas através da indução da expressão de genes (MARX, 2004).

As tecnologias atuais de enxerto ósseo utilizam o potencial osteoprogenitor das CMIs e dos FCs, isolados ou em combinação, para a reparação de

'Departamento de Clínica e Cirurgia Veterinária, Escola de Veterinária, Universidade Federal de Minas Gerais (UFMG). Rua Piauí, 792, ap.1001, Bairro dos Funcionários, 30150-320, Belo Horizonte, MG, Brasil. E-mail: geanepagliosa@gmail.com. *Autor para correspondência. 
fraturas ósseas. Os CMIs podem ser obtidos de vários tecidos orgânicos e os FCs do plasma rico em plaquetas.

O objetivo desta revisão é descrever a função, as técnicas de obtenção, a utilização e o mecanismo de ação das CMIs e dos FCs como recentes tecnologias utilizadas em enxerto ósseo.

\section{FATORES DE CRESCIMENTO}

Os FCs que atuam no tecido ósseo podem ser de origem local ou sistêmica (Tabela 1). Os FCs locais são secretados por células ósseas e difundemse no meio extracelular ou são armazenados na matriz calcificada, sendo recrutados, respectivamente, de forma imediata ou tardia, em casos de injúria tissular (MILLIS, 1999). Os FCs locais e sistêmicos atuam nas fases de inflamação, reparo e remodelamento, durante a cicatrização óssea, exercendo funções importantes em cada uma dessas fases.

Durante a fase inflamatória, o coágulo no foco de fratura contém plaquetas, fibrina, cininas e prostaglandinas (REMEDIOS, 1999). As plaquetas liberam o fator de crescimento derivado de plaquetas (PDGF), que é quimiotáxico para macrófagos e fibroblastos que, ao chegarem ao foco da lesão, liberam mais PDGF, além de fator de crescimento transformador beta (TGF $\beta$ ) e fator do crescimento fibroblástico (FGF). Adicionalmente, os macrófagos fagocitam fragmentos celulares e os osteoclastos reabsorvem células necrosadas e matriz óssea calcificada. Os FCs estocados na matriz óssea - IGF-II, BMPs TGF $\beta$ - são liberados, iniciando-se a fase de reparo ósseo.

Na fase de reparo, ocorrem angiogênese e liberação dos FCs pelas células endoteliais, que também são fonte de células osteoprogenitoras. Células mesenquimais indiferenciadas (CMIs), fibroblastos e macrófagos iniciam a formação do calo periosteal. A proliferação, diferenciação, modulação e coordenação de células no calo ósseo ocorrem através da interação de vários fatores de crescimento, coordenando a mitose celular e a síntese proteica. A mitose celular ocorre por osteoindução de células mesenquimais indiferenciadas, presentes na medula óssea e na circulação sangüínea, em células osteoprogenitoras. Os peptídios BMPs e TGF $\beta$ são os principais fatores de crescimento responsáveis pelo recrutamento e diferenciação das CMIs para a formação do calo duro e posterior formação de osso lamelar durante a fase de remodelamento (MILLIS, 1999).

Potencial terapêutico dos fatores de crescimento A atividade dos FCs na biologia das fraturas fez surgir a hipótese de um possível potencial terapêutico como enxerto ósseo único ou combinado a outros enxertos. O plasma rico em plaquetas (PRP) é a fonte de FCs mais utilizada em enxertos ósseos, fornecendo dois dos principais FCs envolvidos no reparo ósseo: PDGF e TGF $\beta$. Adicionalmente, o PRP pode ser obtido e aplicado ao foco de fratura por técnicas relativamente simples e pouco onerosas (OYAMA et al., 2004).

No entanto, apesar da eficácia do PRP em estimular a diferenciação de células mesenquimais indiferenciadas em células osteoprogenitoras in vitro, alguns estudos que avaliaram sua utilização como enxerto ósseo isolado ou em combinação com outros enxertos in vivo têm resultados controversos (FREYMILLER \& AGHALOO, 2004). Essa controvérsia

Tabela 1 - Fatores de crescimento relacionados ao reparo ósseo.

\begin{tabular}{|c|c|c|}
\hline Fator de Crescimento & Fonte & Funções \\
\hline $\begin{array}{l}\text { Derivado de plaquetas } \\
\text { (PDGF) }\end{array}$ & $\begin{array}{l}\text { Plaquetas, macrófagos, } \\
\text { endotélio, fibroblastos }\end{array}$ & $\begin{array}{l}\text { Quimiotaxia de macrófagos e fibroblastos, proliferação fibroblástica, angiogênese, } \\
\text { mitose de fibroblastos e osteoblastos }\end{array}$ \\
\hline Fibroblástico (FGF) & $\begin{array}{l}\text { Endotélio, macrófagos, } \\
\text { osso, condrócitos }\end{array}$ & $\begin{array}{l}\text { Mitose de células endoteliais, fibroblastos, condrócitos e osteoblastos, angiogênese, } \\
\text { deposição de colágeno }\end{array}$ \\
\hline Epidermal (EGF) & $\begin{array}{l}\text { Plaquetas e outros } \\
\text { tecidos }\end{array}$ & $\begin{array}{l}\text { Quimiotaxia para células endoteliais e fibroblastos, angiogênese e estímulo à } \\
\text { atividade da colagenase }\end{array}$ \\
\hline Transformador $\beta$ (TGF $\beta$ ) & $\begin{array}{l}\text { Plaquetas, macrófagos, } \\
\text { condrócitos, rins, matriz } \\
\text { óssea, osteoblastos }\end{array}$ & $\begin{array}{l}\text { Mitogênico para fibroblastos, condroblastos e osteoblastos, quimiotaxia, síntese de } \\
\text { colágeno e função osteoblástica, síntese de outros fatores de crescimento, } \\
\text { diferenciação de células mesenquimais indiferenciadas }\end{array}$ \\
\hline $\begin{array}{l}\text { Proteína óssea } \\
\text { morfogenética (BMP) }\end{array}$ & $\begin{array}{l}\text { Osteoblastos, matriz } \\
\text { óssea }\end{array}$ & $\begin{array}{l}\text { Diferenciação de células mesenquimais indiferenciadas em condrócitos e } \\
\text { osteoblastos, quimiotaxia de células mesenquimais }\end{array}$ \\
\hline $\begin{array}{l}\text { Somatrotrofina } \quad(\mathrm{STH} \\
[\mathrm{GH}])\end{array}$ & Pituitária anterior & $\begin{array}{l}\text { Anabolismo, crescimento das epífises, proliferação de osteoblastos, produção de } \\
\text { IFG-I }\end{array}$ \\
\hline $\begin{array}{l}\text { Semelhante à insulina } \\
\text { (IGF-I) }\end{array}$ & $\begin{array}{l}\text { Fígado, osteoblastos, } \\
\text { condroblastos, matriz } \\
\text { óssea, fibroblastos }\end{array}$ & Síntese de colágeno e proteoglicanos, proliferação de fibroblastos e osteoblastos \\
\hline
\end{tabular}

(Fonte: Adaptado de MILLIS, 1999).

Ciência Rural, v.37, n.4, jul-ago, 2007. 
é atribuída, em grande parte, a técnicas inadequadas de obtenção de PRP autólogo (MARX, 2004). Por outro lado, a utilização de PRP homólogo, disponível comercialmente em alguns países, não constitui uma vantagem, pois não melhora os índices de regeneração tissular, sendo, por isso, contra-indicado por alguns autores (MARX, 2004; WISLTFALK et al., 2004). Portanto, torna-se fundamental o conhecimento da obtenção e do preparo corretos do PRP para avaliar sua eficácia como enxerto ósseo.

Metodologia de obtenção e utilização do plasma rico em plaquetas

O plasma rico em plaquetas é obtido através de centrifugação do sangue. O resultado é uma concentração acentuada de plaquetas em um reduzido volume plasmático. O PRP contém sete FCs e três proteínas - fibrina, fibronectina e vitronectina - que atuam como moléculas de adesão celular nos processos de migração eptelial, osteoindução e na formação de matriz óssea e de tecido conjuntivo (MARX, 2004).

O PRP deve ser sempre autólogo devido ao risco de rejeição ou à impossibilidade de secreção de fatores de crescimento ativo (MARX, 2004). O sangue a ser utilizado deve ser colhido de maneira asséptica em tubos contendo, preferencialmente, citrato como anticoagulante (CAMARGO et al., 2002). A manipulação do sangue durante a centrifugação deve ser realizada de forma cuidadosa e em rotação adequada para assegurar a separação das células plaquetárias de outras e para evitar ruptura ou danos à sua membrana. A centrifugação pode ser realizada de maneira única ou repetida em duas etapas.

A centrifugação única consiste em submeter o sangue à rotação de 5600rpm, durante seis minutos, ao final do que haverá a formação de três frações. A fração superior conterá o plasma pobre em plaquetas (PPP), a fração mediana o PRP e a fração inferior os eritrócitos. A fração superior contendo o PPP deve ser descartada. A fração mediana, rica em plaquetas, deve ser separada, juntamente com 1 a $2 \mathrm{~mm}$ da fração inferior, para ser utilizada na região óssea a ser implantada (CAMARGO et al., 2002).

A centrifugação repetida em duas etapas foi utilizada por OYAMA et al. (2004) com resultados igualmente positivos. O sangue colhido é centrifugado a $160 g^{a}$ por 20 minutos, e o plasma sobrenadante resultante, juntamente com $6 \mathrm{~mm}$ da fração vermelha, é centrifugado a $400 \mathrm{~g}$ por 15 minutos. Após a segunda centrifugação, o sobrenadante de coloração amarela é descartado, e o material resultante é utilizado para o enxerto (OYAMA et al., 2004).
Anteriormente à incorporação do PRP na área de implante, é necessária a adição de um fator coagulante. Utilizam-se trombina bovina a $100 \mathrm{Uml}^{-1}$ combinada com cloridrato de cálcio a 10\% (CAMARGO et al., 2002) ou fibrina humana (OYAMA et al., 2004). A função é formar uma rede de fibrina incorporada ao PRP capaz de permitir sua aderência ao local do implante, bem como impedir a migração de células epteliais e do tecido conjuntivo para fora da região de enxerto (CAMARGO et al., 2002; LEKOVIC et al., 2003; OYAMA et al., 2004).

A concentração de plaquetas no PRP para fins terapêuticos deve ser significativamente maior que a plasmática para proporcionar a liberação adequada de FCs no local do enxerto. Segundo MARX (2004), a concentração ideal de plaquetas no PRP deve ser em média de 1.000.000 $\mathrm{ll}^{-1}$, em uma alíquota padrão de $6 \mathrm{ml}$.

\section{CÉLULASMESENQUIMAISINDIFERENCIADAS}

A medula óssea é um dos tecidos orgânicos mais ricos em células mesenquimais indiferenciadas (CMIs), também chamadas de células-tronco. Em fraturas, as CMIs atuam na recuperação óssea através da formação de calo ósseo por meio de osteoindução migrando para o foco de fratura, onde diferenciam-se em condroblastos e osteoblastos, especialmente em resposta ao estímulo dos FCs (MARTINEZ \& WALKER, 1999; REMEDIOS, 1999).

Potencial terapêutico das células mesenquimais indiferenciadas

Assim como os FCs, as CMIs são atualmente muito pesquisadas como alternativa terapêutica em enxertos ósseos, mas, ao contrário daqueles, não há controvérsias quanto à sua eficácia na recuperação óssea.

Os efeitos positivos das CMIs na recuperação óssea em fraturas estão documentados em alguns estudos recentes. As CMIs são capazes de recrutar FCs ao foco de fratura, estimulando, assim, o recrutamento adicional de outras CMIs presentes no tecido ósseo (MILLIS, 1999; JAVAZON et al., 2004). Apesar dessa capacidade, a ação osteogênica das CMIs, quando combinadas com FCs em enxertos ósseos, foi mais eficiente (BARRY \& MURPHY, 2004). Por outro lado, o ambiente tissular ou molecular desfavorável pode inibir ou mesmo alterar a função osteogênica das CMIs, estimulando-as à produção de cicatriz (STOCUM, 2001). 
Metodologia de obtenção das células mesenquimais indiferenciadas

As CMIs utilizadas em enxertos ósseos são obtidas principalmente através de aspirado de medula óssea (TUAN et al., 2003). Ao contrário dos FCs, a técnica de obtenção das CMIs é onerosa e complexa, pois envolve cultivo celular. O cultivo é necessário porque as CMIs estão presentes em quantidade reduzida na medula óssea (GAMRADT \& LIEBERMAN, 2004).

A medula óssea colhida é colocada em um meio de cultura específico para a obtenção das CMIs. Após o isolamento e a purificação das CMIs, estas são expandidas e repassadas a outro meio de cultura para proporcionar uma proliferação adequada para posterior utilização em transplantes (GAMRADT \& LIEBERMAN, 2004). No entanto, a proliferação pode ser prejudicada pela dificuldade de reproduzir essas células in vitro (STOCUM, 2001; KREBSBACH \& ROBEY, 2002; HEGEWALD et al., 2004).

\section{CONCLUSÕES}

O conhecimento crescente dos eventos moleculares e celulares envolvidos na recuperação óssea em fraturas permitiu ampliar as possibilidades terapêuticas em enxertos ósseos. Apesar dos resultados contraditórios no uso do plasma rico em plaquetas como fonte de fatores de crescimento, há um evidente potencial de seu uso como estimulador na osteogênese em focos de fraturas. No entanto, há necessidade de padronização na obtenção e emprego desse material como enxerto ósseo, considerando-se que a técnica de produção é relativamente simples e de custo baixo.

Por outro lado, a utilização de células mesenquimais indiferenciadas exige isolamento e cultivo celulares, o que demanda infra-estrutura e qualificação técnica mais específica. Sendo assim, a utilização das células mesenquimais poderia ser limitada a defeitos ósseos com considerável perda de matriz óssea e, portanto, de mais difícil recuperação, como em casos de doença periodontal concomitante com osteíte alveolar ou em regiões com seqüelas de osteomielite. Nesses casos, poder-se-ia considerar a associação de células mesenquimais indiferenciadas ao plasma rico em plaquetas.

Adicionalmente, as novas tecnologias de enxertos ósseos estão proporcionando o entendimento das interações sutis que ocorrem nos eventos de reparo, ampliando as possibilidades terapêuticas em enxertos ósseos e criando novas expectativas na recuperação óssea em situações que, anteriormente, eram tidas como irreparáveis.

\section{FONTESDEAQUISIÇÃO}

a- g: Força Centrífuga do Rotor; FCR $=\left(1,118 \times 10^{-5}\right)$. r (raio do eixo da centrífuga) . $\mathrm{n}^{2}$ (rotação/minuto)

\section{REFERÊNCIAS}

BARRY, P.F.; MURPHY, J.M. Mesenchymal stem cells: clinical applications and biological characterization. Intern J Bioch Cell Biol, v.36, p.568-584, 2004.

CAMARGO, P.M. et al. Platelet-rich plasma and bovine porous bone mineral combined with guided tissue regeneration in the treatment of intrabony defects in humans. J Period Res, v.37, p.300-306, 2002.

FREYMILLER, E.G.; AGHALOO, T.L. Platelet-rich plasma: ready or not? J Oral Maxill Surg, v.62, p.484-488, 2004.

GAMRADT, S.C.; LIEBERMAN, J.R. Genetic modification of stem cells to enhance bone repair. Annals Biom Enginnering, v.32, p.136-147, 2004.

HEGEWALD, A.A. et al. Hyaluronic acid and autologous synovial fluid induce chondrogenic differenciation of equine mesenchymal stem cells: a preliminary study. Tissue and Cell, v.34, p.431-438, 2004

JAVAZON, E.H. et al. Mesenchymal stem cells: paradoxes of passing. Experimental Hematol, v.32, p.414-425, 2004.

KREBSBACH, P.H.; ROBEY, P.G. Dental and skeletal stem cells: potential cellular therapeutics for craniofacial regeneration. J Dental Educ, v.66, p.766-773, 2002.

LEKOVIC, V. et al. Effectiveness of a combination of plateletrich plasma, bovine porous bone mineral and guided tissue regeneration in the treatment of mandibular grade II molar furcations in humans. J Clin Periodontol, v.30, p.746-751, 2003.

MARTINEZ, S.A.; WALKER, T. Bone grafts. Vet Clin North Am Small Anim Pract, v.29, p.1207-1220, 1999.

MARX, R.E. Platelet-rich plasma: evidence to suport its use J Oral Maxillofac Surg, v.62, p.489-496, 2004

MILLIS, R. Bone and non-bone-derived growth factors and effects on bone healing. Vet Clin North Am Small Anim Pract, v.29, p.1221-12466, 1999.

OYAMA, T. et al. Efficacy of platelet-rich plasma in alveolar bone grafting. Am Assoc Oral Maxill Surg v.62, p.555-558, 2004 .

REMEDIOS, A. Bone and bone healing. Vet Clin North Am Small Anim Pract, v.29, p.1029-1044, 1999.

STOCUM, D.L. Stem cells in regenerative biology and medicine. Wound Repos Regen, v.9, p.429-442, 2001.

TUAN, R.S. et al. Adult mesenchymal stem cells and cell-based tissue engineering. Arth Res Ther v.5, p.32-45, 2003.

WISLTFALK, J. et al. Effects of platelet-rich plasma no bone healing in combination wih autogenous bone and bone substitutes in critical-size defects. Clin Oral Implant Res, v.15, p.187193, 2004. 